\title{
Nuevas configuraciones de las posdictaduras en América Latina
}

\author{
ANALÍA GERBAUDO Universidad Nacional del Litoral - CONICET, Argentina / agerbaudo@fhuc.unl.edu.ar
} /analia.gerbaudo@conicet.gov.ar

«Defender la democracia» es el título de la nota que Juan Pascual, periodista y profesor de la Universidad Nacional del Litoral, publica en el periódico Pausa fundado hace ya 12 años y en el que colaboran, entre otros, algunos de los escritores jóvenes que, desde esta ciudad, marcan la literatura argentina actual. El supuesto es obvio: se defiende lo que está en peligro. Pero se trata de un peligro que asecha de modo sutil: diferente a los «viejos formatos de ferretería pesada» (7), los más recientes golpes de Estado en América Latina (pienso en Paraguay, en Brasil y en Bolivia) se presentan como la consecuencia institucionalmente reparadora de hechos aberrantes ( No nos salven», repetía infatigablemente Eduardo Galeano, por si acaso, para desalentar cualquier tentativa de intervención norteamericana en la zona - esas que realizan en nombre de la restitución de los valores democráticos en los Estados considerados «fallidos» [Chomsky 2006]—). Los números son abrumadores, aun cuando solo se tomen las cifras del siglo XXI: «2002 en Venezuela, fallido; 2004, Haití, triunfante; 2008, Bolivia, fallido; 2009, Honduras, triunfante; 2010, Ecuador, fallido; 2012, Paraguay, triunfante; 2016, Brasil, triunfante; 2019, Bolivia, triunfante» (7). En la serie, el caso de Chile se impone dado que, como afirman los investigadores que firman la carta que menciono a continuación, desde octubre de 2019 se ha vivido en una suerte de Terrorismo de Estado dentro de un orden «democrático».

A mediados de noviembre de 2019, Raúl Rodríguez Freire nos hizo llegar una carta dirigida a Michelle Bachelet Jeria en tanto Alta Comisionada de Derechos Humanos ante la Organización de las Naciones Unidas. Los números, otra vez, impresionan: «En 23 días, desde el 17 de octubre [de 2019], el Instituto de Derechos Humanos [de Chile] ha constatado 23 muertos, 5.565 detenidos, 1.915 heridos en hospitales por disparos de bala, perdigones y otras armas, 182 personas con heridas oculares y 262 querellas criminales en contra de carabineros, entre ellas, 171 por torturas y tratos crueles y 52 por violencia sexual, así lo atestiguan». El resaltado en negrita remarca el hecho de que, hasta la fecha de escritura de la carta, «las policías chilenas» se habían cargado un muerto por día desde el comienzo de la represión a los manifestantes que luchaban por la reforma de la Constitución de ese país junto a los estudiantes que, sintomáticamente, habían salido a las calles luego del aumento del precio del boleto del subte.

\footnotetext{
Para citar este artículo: Gerbaudo, A. (2020). Nuevas configuraciones de las posdictaduras en América
} Latina. El taco en la brea, 11 (diciembre-mayo), 2-5. Santa Fe, Argentina: UNL. DOI: 10.14409/tb.v1i11.9149 
En Argentina, y por circunscribir el problema de los efectos de la gestión del gobierno de la alianza Cambiemos a los campos de la producción científica y cultural, sociólogos y antropólogos que, por profesión, extraen las conclusiones de sus investigaciones a partir de rigurosos datos estadísticos, observaciones y otros trabajos de campo, exponen diagnósticos demoledores. En el prólogo a la documentadísima investigación de Daniela Szpilbarg, Cartografía argentina de la edición mundializada. Modos de hacer y pensar el libro en el siglo XXI, Gustavo Sorá hace referencia al panorama desolador en el que estos resultados se publican, por noviembre de 2019: «La lectura de una investigación básica como la tramada por Daniela Szpilbarg en este libro motiva regocijo, esperanza. El libro aparece en un momento crítico de la ciencia y la cultura en Argentina; por ello redobla el significado de estos engranajes del pensamiento para ordenar, calibrar y dudar sobre la génesis, las derivas y destinos de nuestra comunidad imaginada» (7).

Por su parte Szpilbarg, en su riguroso estudio de la configuración del campo editorial en Argentina entre la década del noventa y 2015 (con algunos agregados ligados al momento de cierre de la investigación: hay apartados que, deliberadamente, extienden el análisis hasta 2018 y otros incluyen datos construidos en 2019), corre un par de riesgos y toma un conjunto de decisiones que se imponen como modélicas para quienes trabajamos en esa zona de borde disciplinar insinuada entre las ciencias sociales y humanas: se atreve con una periodización "posible» (107) del campo editorial que elabora a partir de la combinación de variables económico-políticas con acontecimientos específicos; se vale de un conjunto estratégico de entrevistas a agentes cuyos nombres y apellidos repone (dejo para otra oportunidad el detalle de las controversias desatadas por una investigación en curso en el campo de las letras alrededor de la decisión de mencionar el nombre de los entrevistados al momento de publicar los resultados [cf. Gerbaudo]); intersecta entrevistas y observaciones a los efectos de obtener «información clave para producir datos e hipótesis» (16). Más allá de esta somera caracterización de algunas de sus estrategias metodológicas, quisiera detenerme en un punto conectado con el tema que vengo anticipando: en su análisis de la intrincada retícula de poderes fortificada por las políticas neoliberales de los años noventa como por algunas de las que vinieron después, vuelve sobre el «golpe de mercado» contra el gobierno democrático de Raúl Alfonsín que lee en clave de intereses en juego y de luchas de campo impulsadas por sectores consolidados durante la última dictadura. Vale la pena traer la cita completa para que se pueda apreciar cómo un análisis que terminará haciendo eje en el campo editorial tal como se configura en Argentina entre los noventa y 2015, intersecta elementos que se definen a nivel nacional y supranacional en una dinámica descripta desde un cuidado e inteligente estructuralismo a la Bourdieu que exige la trabajosa puesta de manifiesto de las relaciones que Szpilbarg desnuda:

En este contexto, el poder económico fortalecido durante la dictadura comenzó a perseguir algunos objetivos: por un lado, asegurar un apoyo destinado a consolidar ámbitos privilegiados de acumulación insertos en el «complejo estatal privado» y, por otro lado, obstaculizar la puesta en marcha de mecanismos redistributivos. Este segundo objetivo buscaba demostrar que el poder de las corporaciones era grande en comparación con la potestad del Estado democrático para llevar adelante un rol protagónico y realizar algunas tareas como la reindustrialización, el desarrollo económico y la redistribución del ingreso.

En estas condiciones emergió el gobierno menemista que tomó anticipadamente el poder. Así comenzó el plan que incluyó el fin del intervencionismo estatal a través de una serie de medidas: el ajuste fiscal, 
la desregulación de los mercados de bienes y servicios, la flexibilización de la contratación laboral, la privatización de empresas estatales y la apertura comercial y financiera. (50)

Desde hace algunos años investigadores de Argentina, Brasil y España armamos una red informal de discusión alrededor de un término que empleamos en nuestras investigaciones: "posdictadura» (Antelo, Schwarzböck, Hidalgo Nácher, Maradei). Un concepto que usamos para llamar la atención sobre tiempos marcados por huellas de otros. Como José Rabasa cuando esgrime sus razones para hablar de "poscolonialismo», reiteramos que el prefijo "pos» subraya "continuidades y legados» (220) entre un momento y otro: no se trata, de ninguna manera, de la simple referencia a lo que viene después.

No me distraje. Intento alentar, por esta vía, las investigaciones en curso sobre las posdictaduras y sus nuevas configuraciones. Se trata, se sabe, de trabajos que alojan un concepto inquietante de hechura compleja que exige, para su composición, el tipo de estudio que Szpilbarg realiza, por ejemplo, para problematizar y afinar el concepto de edición «independiente» y/o para elaborar la ya mencionada periodización sobre la que pareciera agregar, a modo de ademán preventivo ante alguna crítica por-venir, el adjetivo «posible».

En 2009 Rossana Nofal cerraba el II Workshop Internacional de Investigadores Jóvenes «La gravitación de la memoria: testimonios literarios, sociales e institucionales de las dictaduras en el Cono Sur» celebrado en la Universidad Nacional de Tucumán equiparando «investigar» con «correr riesgos». Su definición mueve a ir «más allá de», tal como aprendimos de Jacques Derrida a ir «más allá de» una frontera o un límite o un estado de las cosas cuando esa frontera o ese límite o ese estado de las cosas obstaculiza un desarrollo que se avizora promisorio. Justamente en ese sentido corre riesgos Daniela Szpilbarg cuando toma sus osadas decisiones metodológicas. Corren riesgos Fernanda Beigel y Gustavo Sorá cuando recurren a una dicotomía cuestionada al designar como «coalición de derecha» (328) a la alianza que gobernó Argentina entre 2015 y 2019. Corre riesgos Juan Pascual cuando arma y sostiene Pausa desde una patricia y conservadora ciudad de provincia. Corren riesgos Francisco Bitar, Santiago Venturini y Larisa Cumin cuando escriben una literatura que rompe el molde, en parte, porque no negocia nada. ¿Por qué entonces no correrlos para intentar contribuir a modelar un concepto con promesa heurística productiva para nuestras investigaciones por-venir (esas que se obstinan con analizar las marcas del pasado en las constricciones del presente)?

\section{Referencias bibliográficas}

Antelo, R. (2016). Programa para un posgrado futuro. El taco en la brea, (3), 144-171.

Beigel, F. y Sorá, G. (2019). Arduous Institutionalization in Argentina's SSH: Expansion, Asymmetries and Segmented Circuits of Recognition. Shaping Human Science Disciplines. Socio-Historical Studies of the Social and Human Sciences (327-360). London: Palgrave Macmillan.

Chomsky, N. (2006). Estados fallidos. El abuso de podery el ataque a la democracia. Buenos Aires: Ediciones B. Traducción de Gabriel Dols.

Gerbaudo, A. (2018). El fuego, el agua, la biodegradabilidad. Apuntes metodológicos para un archivo porvenir. En Arán, P. y Vigna, D. (Dirs.). Archivos, artes y medios digitales. Teoría y práctica (41-65). Córdoba: Centro de Estudios Avanzados-UNC. https://rdu.unc.edu.ar/handle/11086/6736?show=full 
Hildago Nácher, M. (2020). Hacia una historia de la teoría en España: un estado de la cuestión.

En Gerbaudo, A. y Hidalgo Nácher, M. (Eds.). Los estudios literarios en Argentina y en España:

institucionalización e internacionalización. Barcelona/Santa Fe: UB/UNL (e-book en proceso de edición).

Maradei, G. (2020). Contiendas en torno al canon. Las historias de la literatura argentina posdictadura. Buenos Aires: Corregidor.

Pascual, J. (2019). Defender la democracia. Pausa, (244), 7.

Rabasa, J. (2009). Poscolonialismo. Diccionario de Estudios Culturales Latinoamericanos (219-223). México: Siglo XXI/Instituto Mora.

Schwarzböck, S. (2016). Los espantos. Estética y postdictadura. Buenos Aires: Cuarenta Ríos.

Sorá, G. (2019). Prólogo. En Szpilbarg, D. Cartografía argentina de la edición mundializada: modos de hacery pensar el libro en el siglo XXI (7-11). Temperley: Tren en movimiento.

Szpilbarg, D. (2019). Cartografía argentina de la edición mundializada: modos de hacery pensar el libro en el siglo XXI. Temperley: Tren en movimiento. 